\title{
Comparative analysis of the effectiveness of tuberculosis prophylaxis in patients with HIV/AIDS treated with isoniazid
}

\author{
Konrad Juszkiewicz ${ }^{1,2, A, C-E}$, Mirosław J. Jarosz ${ }^{3,4, A, C, E}$, Anna Włoszczak-Szubzda ${ }^{3,4, A-F}$, \\ Magdalena Głowacka ${ }^{3, C-D}$ \\ ${ }^{1}$ National Medical University, Kazakhstan \\ ${ }^{2}$ KIT Royal Tropical Institute, The Netherlands \\ ${ }^{3}$ University of Economics and Innovation, Lublin, Poland \\ ${ }^{4}$ Institute of Rural Health, Lublin, Poland \\ A - Research concept and design, B - Collection and/or assembly of data, C - Data analysis and interpretation, \\ $D$ - Writing the article, E-Critical revision of the article, F - Final approval of article
}

\begin{abstract}
Juszkiewicz K, Jarosz MJ, Włoszczak-Szubzda A, Głowacka M. Comparative analysis of the effectiveness of tuberculosis prophylaxis in patients with HIV/AIDS treated with isoniazid. Ann Agric Environ Med. 2019; 26(3): 462-467. doi: 10.26444/aaem/106765
\end{abstract}

\begin{abstract}
Introduction. The epidemic of human immunodeficiency virus has had a tremendous effect on the epidemic of tuberculosis. Together with the spread of HIV, a great increase has been observed in morbidity due to tuberculosis, both in endemic countries and in those where earlier, as a result of treatment, the frequency of occurrence of tuberculosis had decreased. In 2018, the WHO data demonstrated that the EECA region was the only region worldwide where the epidemics of HIV was still rapidly increasing. The EECA region still struggles with a serious epidemic of tuberculosis.

Materials and method. The research method applied was comparative analysis of the results of own study and studies by other researchers, concerning the effectiveness of tuberculosis prophylaxis in patients with HIV/AIDS when treated with isoniazid.

Results. In own study, it was found that primary morbidity among patients administered isoniazid significantly decreased within 5 years. Incidence rates of primary morbidity were significantly lower than among patients who had not received isoniazid. Relevant studies conducted worldwide, in many cases differed from own study with respect to both the results and approach to the problem, by country or selection of the type of patients participating in the study. However, in all studies, isoniazid was generally a safe and well-tolerated drug, without special side-effects.

Conclusions. All studies analyzed concerning the effectiveness of tuberculosis prophylaxis in patients with HIV/AIDS treated with isoniazid, confirmed the effectiveness of this drug. In the compared studies, applied isoniazid preventive therapy showed no difference in effectiveness according to its duration. Analyzed studies showed similar effectiveness also with respect to a decrease in mortality among patients with TB/HIV/AIDS.
\end{abstract}

\section{Key words}

HIV, AIDS, isoniazid, tuberculosis prophylaxis

\section{INTRODUCTION}

In Eastern Europe, epidemics of tuberculosis (TB) and infections with HIV have developed independently. Approximately 10 years ago, in a part of patients ill with TB, the disease was not related with the immunosuppression characteristic of patients infected with HIV/AIDS (PLW HA). The risk of TB in PLW HA is higher in the regions where it is more prevalent.

According to reports and scientific publications, at the end of 2017, in the countries of Eastern Europe and Central Asia (EECA), tuberculosis was the disease most frequently diagnosed together with AIDS. Tuberculosis (TB) was diagnosed in approx. 1.4 million patients with HIV infection, this concerns cases diagnosed for the first time in the discussed area (EECA) $[1,2,3,4,5]$.

Staying in places of detention increases the risk of TB and HIV. This is caused by the factors of the surrounding

Address for correspondence: Anna Włoszczak-Szubzda, University of Economics and Innovation, Lublin, Poland

E-mail: a-wlos@tlen.pl

Received: 13.02.2019; accepted: 10.04.2019; first published: 25.04.2019 environment and poor nutrition. Prison conditions increase susceptibility and sensitivity of prisoners to these infections, and contribute to even more risky behaviours. Overpopulation, staying in an enclosed space, poor ventilation, limited access to natural light (ultraviolet) and long contact with persons ill with TB facilitate airborne transmission of this infection. The behaviours common in prisons, non-hygienic methods of taking injection drugs, tattoos, and sexual contacts without proper protection, considerably increase the risk of infection with HIV, as well as hepatitis B and C viruses $[6,7,8]$.

The epidemic of human immunodeficiency virus exerted a tremendous effect on epidemic of tuberculosis. Together with the spread of HIV, a great increase has been observed in morbidity due to tuberculosis, both in endemic countries and in those where earlier, due to TB treatment, the frequency of occurrence of tuberculosis, had decreased [9]. In 2018, the WHO data demonstrated that the EECA region was the only region worldwide where the epidemics of HIV was still rapidly growing, with a $30 \%$ increase in annual HIV infections during the period 2010-2017 [10, 11]. In 2017, there were approximately 190,000 new cases of HIV infection, by 80,000 more than in 2013 . In the same year, there were 
40,000 deaths due to AIDS (by $22 \%$ more than in 2010). By the end of $2017,73 \%$ of patients living with HIV were aware of their HIV status, which increased by $4 \%$ from 2016 [12].

The EECA region still struggles with a serious epidemic of tuberculosis. Considering absolute numbers, in 2016, Russia had the highest number of patients with tuberculosis - on the level of 94,000, followed by Ukraine - 39,000, and Kazakhstan - 12,000 [13]. Despite this, in many countries of the EECA region, the rates concerning new cases of tuberculosis infection decline considerably more rapidly than globally (by 1.9\%; globally - 1.5\%). The highest annual decrease during the period 2007-2017 concerned Kazakhstan $(-9.4 \%)$ and Tajikistan $(-7.4 \%)[13,14]$.

It is noteworthy that the probability of the development of TB in persons infected with HIV is by $20-37$ times higher than among the population not infected with HIV. The risk of contracting TB among those not infected with HIV is estimated at 5-10\% during whole life, while the risk of falling ill with TB among persons infected with HIV is $5-10 \%$ each year [14]. HIV seropositive persons receive preventive treatment with isoniazid (INH) in only $21 \%$ of countries worldwide. From among 41 countries with a high level of infection with tuberculosis/HIV, this therapy is available in only 14 countries $[15,16]$. In 2017 , only $3 \%$ of the total expenditures on HIV in the EECA region were allocated for programmes focused on the TB/HIV population [17].

\section{OBJECTIVE}

The aim of the study was to compare the results of own study with those obtained by other researchers, published during the period 2015-2018 concerning the effectiveness of tuberculosis prophylaxis in patients with HIV/AIDS treated with isoniazid.

\section{MATERIALS AND METHOD}

The research method applied was comparative analysis of the results of own study and studies by other researchers, concerning the effectiveness of tuberculosis prophylaxis in patients with HIV/AIDS treated with isoniazid. In own study, the selection of the groups was as follows:

- Two groups of patients with HIV under dispensary observation in the Centre for AIDS Prevention and Control in the city of Almaty, Kazakhstan.

- Patients who had undergone complete TB chemotherapy during the period 2010-2011 - 323 patients infected with HIV:

- 136 patients who received isoniazid in 2010;

- 187 patients who received isoniazid in 2011.

The control group of persons infected with HIV who did not receive isoniazid in 2010-2011 comprised 325 patients. A complete retrospective analysis was performed of the medical history for each of the 648 patients, starting from 2010-2011 until 2015, inclusive. Data was collected using ambulatory medical records of patients infected with HIV who were under observation in the Centres for AIDS Treatment. For each patient, the following data were obtained from the medical record:

- data concerning TB chemoprophylaxis during the years after 2010-2011;

- description of all interventions:

- after diagnosis of TB;

- starting anti-retrovirus therapy (ARV);

- pharmacological treatment ARV programme;

- clinical study of HIV infection;

- determination of indicators of the level of lymphocyte $\mathrm{T}$ - helper cells with CD4+ receptors;

- viral load;

- PCR (polymerase chain reaction);

- RNK (examination of the level of virus replications) HIV;

- cases of tuberculosis;

- costs of treatment of patients ill with tuberculosis;

- mortality of patients;

- time and cause of death;

- separate registration of deaths due to tuberculosis.

For quantitative variables, statistical analysis of the data included: numbers (n), arithmetic mean (M), and standard deviation (SD). For quantitative variables, statistical description of the data included: numbers, absolute frequency of each variable value, relative frequency of each variable value (percentage). For all the investigated qualitative variables, the missing data were not considered while calculating relative frequency. The relationships between discrete variables (qualitative) were verified using the Pearson's chi-squared test. All calculations were performed using the software SPSS version 11.5 (SPSS Inc., Chicago, IL., USA). SAS version 9.2 (Cary, NC). The following studies were compared with own study:

1) Four publications describing the effectiveness of ITP with respect to patients with $\mathrm{TB} / \mathrm{HIV} / \mathrm{AIDS}$, where the total number of patients examined was 4,188 .

2) Four publications describing the level of mortality among patients with TB/HIV/AIDS for whom ITP was applied, where the total number of patients examined was 5,617.

3) Four publications describing the differences between the duration of ITP with respect to patients with TB/HIV/ AIDS, where the total number of the patients examined was 11,358 .

The following criteria of selection were applied in comparative analysis:

- tuberculosis prophylaxis in patients with HIV/AIDS, in the form of treatment with isoniazid; - investigation of the effectiveness of isoniazid prophylaxis;

- examination of the effect of isoniazid on mortality among patients with HIV/AIDS with TB,

- publications concerning studies conducted during 20102018.

\section{RESULTS}

Comparative analysis of research in the area of effectiveness of isoniazid prophylaxis. Own study confirmed that primary morbidity in patients who had received the cycle of TB Isoniazid prophylaxis did not exceed 0.555 cases per 100,000 population during the first year of observation, and subsequently, morbidity decreased down to 0 within 5 years. Primary morbidity rates were considerably lower, compared to patients who had not received isoniazid preventive therapy. In the control group, primary morbidity during the first year 
of observation was 3,262 cases per 100,000 population, with a decrease down to 0.364 in the fifth year. Accumulated morbidity during the period 2011-2015 in the study group was 1,276 cases per 100,000 population, while in the control group accumulated morbidity was 4.3 times higher at 5.527. According to the data from the National Centre for Tuberculosis Problems, morbidity due to TB/HIV in 2014 was 3.4 cases per 100,000 of the population (Figure 1).

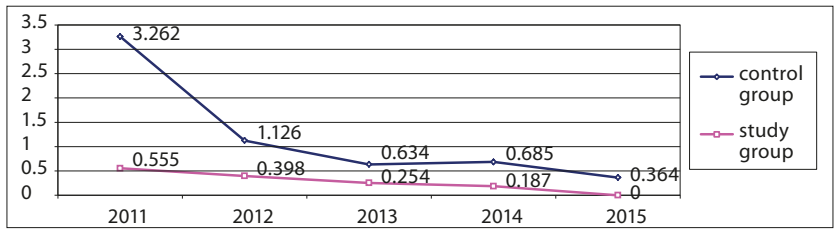

Figure 1. Primary morbidity due to TB in the study group and control group during 2011-2015.

Source: Own study based on: 'Electronic Register and Monitoring of Cases of HIV infection in the RK'.

The first of the studies compared was a retrospective cohort study conducted using data from public health care units in Addis Ababa, Ethiopia, and included 2,524 patients infected with HIV, observed for 4,106 person-years; 277 cases of tuberculosis (TB) were registered. The frequency of occurrence of tuberculosis was $0.21 / 100$ person-years and 7.18 / 100 person-years, respectively, among patients treated and non-treated using IPT. IPT considerably decreased the frequency of occurrence of tuberculosis (by 96.3\%), compared to patients who did not receive IPT [18].

A subsequent retrospective study was conducted in the in the ART clinic of the Arba Minch Hospital in Southern Ethiopia. This study covered all 271 patients using ART, who applied IPT prophylaxis from September 2010 - August 2011 in the ART clinic of Arba Minch Hospital. The results showed that IPT considerably contributed to a reduction in the number of TB infections and the number of T CD4 + cells [19].

In Durban, in the Republic of South Africa, a secondary analysis was conducted using data collected during October 2009 - October 2013, among patients qualified for a prospective cohort study. The study included 402 patients from whom 344 patients were authorized to receive IPT, and 212 initiated IPT therapy. The implementation of IPT among patients with ART and TB was well tolerated, with a good percentage of completion and a smaller number of TB cases diagnosed after performing IPT [20].

In South Africa and Botswana, three trials were conducted including 991 participants aged under 13. The children were qualified at random to isoniazid prophylaxis or placebo, preventive treatment/placebo was administered every day or three times a week. Children with HIV, aged under 13, without tuberculosis (irrespective of previous history of treatment of tuberculosis, TB infection and TB prophylaxis), were enrolled into the study. Randomized controlled trials (RCT) were carried out which evaluated the effectiveness of preventive treatment of tuberculosis in study participants randomly qualified for TB prophylactic treatment and placebo. Isoniazid preventive therapy was administered to all children diagnosed with HIV, which reduced the risk of contracting tuberculosis and the risk of death in children infected with HIV [21].
Comparative analysis of research concerning the effect of isoniazid on mortality in patients with HIV/AIDS with TB. In own study, tuberculosis occupied the first position among diseases leading to death in PLW HA. TB-related mortality was observed in $44.2 \%$ of all deaths (Tab. 1 ). The percentage of males was higher than females. However, among females, considering the causes of death, the percentage of extrapulmonary tuberculosis was slightly higher.

Table 1. Main causes of death among adult patients with HIV infection, according to gender, in Almata 2011-2015

\begin{tabular}{lcccccc}
\hline \multirow{2}{*}{ Main causes of death } & \multicolumn{2}{c}{ Males } & \multicolumn{2}{c}{ Females } & \multicolumn{2}{c}{ Total } \\
\cline { 2 - 7 } & No. & $\%$ & No. & $\%$ & No. & $\%$ \\
\hline Tuberculosis, including extra-pulmonary & 187 & 48.1 & 34 & 30.6 & 221 & 44.2 \\
\hline $\begin{array}{l}\text { Infectious diseases, including } \\
\text { pneumonia }\end{array}$ & 61 & 15.7 & 28 & 25.2 & 89 & 17.8 \\
\hline Hepatitis, liver cirrhosis & 54 & 13.9 & 16 & 14.4 & 70 & 14.0 \\
\hline Oncologic diseases & 47 & 12.1 & 17 & 15.3 & 64 & 12.8 \\
\hline $\begin{array}{l}\text { Non-infectious diseases (cardiovascular, } \\
\text { renal, endocrine, and others) }\end{array}$ & 40 & 10.2 & 16 & 14.5 & 56 & 11.2 \\
\hline Total & 389 & 100.0 & 111 & 100.0 & 500 & 100.0 \\
\hline Test Chi & \multicolumn{5}{c}{ Chi $^{2}=12.4016 ; \mathrm{p}=0.014602$} &
\end{tabular}

Source: Medical records and data from:'Electronic Register and Monitoring of Cases of HIV infection in the RK'

While comparing the structures of causes of death in the study and control groups, a significant difference was observed in the register of deaths due to TB (Tab. 2). The percentage of deaths due to TB among patients who had undergone the cycle of TB prophylaxis was $21.6 \%$, which is nearly three times lower than in the control group (57.0\%), who did not receive isoniazid ( $\mathrm{p}=0.020972)$, and twice as low compared to the total dispensary group (44.2\%); however, this relationship was statistically insignificant $(\mathrm{p}=0.109297)$.

Table 2. Main causes of death among patients in the study group, control group, and total dispensary group, during the period 2011-2015

\begin{tabular}{|c|c|c|c|c|c|c|}
\hline \multirow[t]{2}{*}{ Cause of death } & \multicolumn{2}{|c|}{$\begin{array}{l}\text { Study group } \\
\qquad n=37\end{array}$} & \multicolumn{2}{|c|}{$\begin{array}{l}\text { Control } \\
\text { group } \\
n=58\end{array}$} & \multicolumn{2}{|c|}{$\begin{array}{l}\text { Total } \\
\text { dispensary } \\
\text { group } \\
\mathrm{n}=500\end{array}$} \\
\hline & No. & $\%$ & No. & $\%$ & No. & $\%$ \\
\hline Tuberculosis & 8 & 21.6 & 33 & 57.0 & 221 & 44.2 \\
\hline $\begin{array}{l}\text { Infectious diseases including } \\
\text { pneumonia }\end{array}$ & 10 & 27.0 & 8 & 13.8 & 89 & 17.8 \\
\hline Hepatitis and liver cirrhosis & 6 & 16.2 & 5 & 8.6 & 70 & 14.0 \\
\hline Oncologic diseases & 7 & 18.9 & 6 & 10.3 & 64 & 12.8 \\
\hline $\begin{array}{l}\text { Non-infectious diseases } \\
\text { (cardiovascular, renal, endocrinal and } \\
\text { others) }\end{array}$ & 6 & 16.3 & 6 & 10.3 & 56 & 11.2 \\
\hline Total & 37 & 100.0 & 58 & 100.0 & \multirow[b]{2}{*}{500} & \multirow[b]{2}{*}{100.0} \\
\hline \multirow[t]{2}{*}{ Chi $^{2}$ tests } & \multicolumn{4}{|c|}{$\begin{array}{l}\text { Study } / \text { Control } \mathrm{Chi}^{2}= \\
11.5566 ; \mathrm{p}=0.020972\end{array}$} & & \\
\hline & Stc & Tot & $\mathrm{Chi}^{2}=$ & .5553 & $=0.1$ & 297 \\
\hline
\end{tabular}

Source: Data from: 'Electronic Register and Monitoring of Cases of HIV infection in the RK'.

Deaths due to diseases were considered while assessing the survival rate of patients with HIV infection. In the study group, the survival rate of patients who had undergone the cycle of TB chemoprophylaxis was higher than in the group 
who did not receive isoniazid. The percentage of patients who did not die due to diseases within 5 years was $88.5 \%$ in the group who received chemoprophylaxis. In the control group, the percentage of such patients was $82.2 \%$.

While comparing the studies, an observation analysis of the cohort was performed using prospective data collected among persons employed in the group of industrial enterprises functioning in South Africa. During the period of 12 months, 3,270 persons were observed - patients with TB infected with HIV/AIDS who received ITP and those who did not receive ITP. The results of the study confirmed a reduced mortality among patients who had received prophylactic treatment with isoniazid which, according to the WHO recommendation, confirmed the necessity for routine application of IPT in the programmes of care of patients with HIV/AIDS with TB [22].

A subsequent study showed annual mortality in patients infected with HIV with tuberculosis susceptible to rifampicin / isoniazid in Eastern Europe, Western Europe and Latin America. In a prospective cohort study, factors related with mortality were analyzed and compared, based on analysis of 341 patients with HIV/AIDS and TB (Eastern Europe 127, Western Europe - 165, Latin America - 49). Despite comparable use of the recommended anti-tuberculosis treatment, mortality among patients with tuberculosis susceptible to rifampicin / isoniazid remained on a higher level in Eastern Europe, compared to Western Europe and Latin America [23].

A study conducted in Sub-Saharan Africa included 1,696 patients with pulmonary tuberculosis, infected and noninfected with HIV/ AIDS. The results of this study also showed that well-planned and supervised anti-retrovirus therapy reduced mortality among patients with tuberculosis / HIV/AIDS [24].

A subsequent, retrospective observation study was conducted in a clinical cohort of patients with HIV-1/AIDS at the National Institute of Infectious Diseases Evandro Chagas, Rio de Janeiro, Brazil. A total number of 310 patients were examined. During the period of study, 64 of the patients died. The mortality rate after initiating preventive tuberculosis treatment was 44 per 100 patients during the first 30 days, 28.1 per 100 patients within 31 and 90 days, 6 per 100 patients within 91 and 365 days, and 1.6 per 100 patients after 365 days. The probability of death within one year from starting preventing tuberculosis treatment was approximately $13 \%$ [25].

Comparative analysis of the effectiveness of ITP according to duration of therapy. In the process of evaluation of the duration of isoniazid preventive therapy, no differences in the effectiveness were detected between the 6 and 12-month periods of therapy $[26,27,28,29]$.

Although 9-month IPT seemed to be the most optimal, which is supported by evidence and recommended in some WHO guidelines, there are no studies which directly compare this period with 6- or 12-month IPT. Two studies from Botswana [30] and the Republic of South Africa [31] suggest greater benefits from the 12-month or longer preventive treatment period, than the 6-month IPT plan, especially in persons who had a positive result in the tuberculin skin test (purified protein derivative skin test PPD). However, no special difference was observed between 6- and 36-month IPT in a clinical study conducted in India [32]. In children living with HIV, with positive or negative PPD, it was confirmed that IPT decreased early mortality by $50 \%$, and the frequency of occurrence of tuberculosis by $70 \%$ [33]. In own study, a 6-month model of TB prophylaxis was adopted, and the results confirmed its effectiveness.

\section{DISCUSSION}

The results of own study confirmed the effect of IPT on reduction in the level of mortality among patients with TB/ HIV/AIDS; however, there are studies with the participation of adults which did not show any health benefits from the use of IPT [34].

Based on the WHO data, only 85,000 PLW HA obtained IPT in 2009, which was only $1.3 \%-6.6$ million PLHIV worldwide. Relatively few countries from the regions of South-East Asia and the West Pacific applied IPT. Very few countries informed the WHO concerning the application of IPT in their TB programmes, and those which did inform about their TB programmes and their effects, and showed this service to be less than 1\% for PLHIV worldwide [35].

In 2010, despite the WHO recommendation, only 600,000 of 1.1 million patients with HIV received chemo-prophylactic treatment, whereas $80 \%$ of the countries did not inform the WHO about initiation of prophylactic treatment [36]. In 2010, Kazakhstan was on the list of countries that implemented IPT in PLHIV patients as a part of the national algorithm of treatment of patients living with HIV.

Isoniazid prophylaxis, both worldwide and in Kazakhstan, despite the WHO recommendations, is far from being perfect. One of the potential causes is the lack of belief in the effectiveness of prophylactic therapy among doctors engaged in TB treatment. This is observed especially in the countries with a high level of TB resistant to antibiotics, and Kazakhstan belongs to this group of countries.

In the published results of a study concerning TB preventive therapy using isoniazid in people living with HIV/AIDS, the objective was to evaluate evidence for using IPT in adults living with HIV, based on a literature review published during 1995-2013. The selected publications contained data concerning adult patients with HIV in countries with low or middle income. Analysis covered mortality, morbidity, and duration of stay in medical facilities of patients with HIV receiving IPT. The costs of treatment versus its effectiveness/ profitability was also analyzed. Analysis included 41 articles with more than 45,000 PLHIV. Despite a small number of evidence, which would confirm that IPT reduces PLHIV mortality, the researchers confirmed that IPT decreases morbidity due to tuberculosis. The obtained results confirmed this trend, irrespective of the number of CD4 or the status of antiretroviral therapy. The studies often showed greater benefits from ITP in patients with a positive TB skin test (PPD). Duration of the effectiveness of IPT and benefits resulting from the duration of treatment differed according to the analyzed publications. This analysis supported the recommendations by the WHO concerning the provision of IPT for PLHIV and reduction of TB-related morbidity [37]. The results of this analysis were fully in accordance with the results of own study.

In 2015, a group of researchers under the direction of Dr. H. T. Ayele studied the effectiveness of prophylactic therapy using isoniazid in patients with HIV. The objective of this project was a systematic review and an overall analysis 
of the effect of IPT in the prevention of tuberculosis in adult patients infected with HIV. The secondary aim was evaluation of the effect of IPT on the progress of AIDS, mortality due to other causes, and adverse drug reactions (ADR), in order to identify appropriate articles available in English from 11 September 2015. The researchers analyzed scientific articles concerning the comparison between IPT and placebo, or cases of the lack of treatment with isoniazid of adult patients infected with HIV, by means of randomized clinical studies. Within the study, the researchers evaluated 10 randomized clinical trials, which included 7,619 patients with HIV, using IPT or placebo. In all studied participants, on average, a $35 \%$ reduction in the $\mathrm{TB}$ risk $(\mathrm{RR}=0.65)$ was observed. The greatest benefit from IPT was noted among patients who had a positive tuberculin test (PPD). Among these patients, the risk of contracting tuberculosis decreased to $52 \%(\mathrm{RR}=0.48)$. No statistically significant effect of IPT was observed on contracting TB by patients with a negative PPD. IPT also decreased the risk of progression of HIV disease to $31 \%$ in all participants $(R R=0.69)$, despite the lack of benefits observed in patients with positive PPD. The application of IPT did not show any effect on the mortality of patients due to other causes, although the participants who received 12-month IPT were usually at a lower risk of death $(\mathrm{RR}=0.65)$. IPT had an elevated (and statistically insignificant) risk of any adverse effect of the drug by $20 \%$ $(\mathrm{RR}=1.20)$. In one study, the effect of IPT was evaluated on the occurrence of multidrug-resistant tuberculosis, and the result suggested that prophylactic treatment with isoniazid might be effectively applied in countries with a high level of drug-resistant tuberculosis. Studies confirmed that the use of IPT, largely contributes to the prevention of tuberculosis in people infected with HIV in general, and especially in the case of patients with positive PPD [38].

The results of own study are almost identical to the abovedescribed analysis. Own study confirmed that the application of TB chemoprophylaxis is effective, and considerably reduces primary morbidity due to tuberculosis. With the use of isoniazid prophylaxis, the occurrence of TB among patients with HIV and accumulated morbidity due to tuberculosis was 3.4-4.8 times lower (mean 35\%), compared to the control group. The deferred effectiveness of TB chemoprophylaxis among patients infected with HIV within 60 months was by $23.8 \%$ higher than the rates in the control group. The application of TB chemoprophylaxis decreased by 4 times the annual accumulated mortality due to tuberculosis, and did not increase the risk of occurrence of drug-resistant tuberculosis, although Kazakhstan belongs to the top 20 countries with the highest level of TB bacteria resistant to antibiotics.

International studies concerning a similar problem, in many cases differed from own study with respect to the results, as well as approach to the problem, by country or selection of the type of patients participating in research.

The common denominator for the majority of studies or projects was the fact that the researchers used national or international databases for analysis of the effectiveness of preventive treatment. In all studies, isoniazid was generally a safe and well-tolerated drug, without special adverse effects. Replies to the questions: 'Is isoniazid preventive therapy effective?', and 'To what extent does it exert an effect on the reduction of mortality and frequency of TB infection in patients with HIV?' overlapped in international and own studies. However, there were some differences in the results of studies, most probably related with the level of the spread of tuberculosis and HIV, as well as the economic situation and level of medical services in a given country or region. Kazakhstan is one of the countries with a high level of TB bacteria resistant to isoniazid and rifampicin (more than $20 \%$ ). Opposite to the above-described studies, in own study no results were observed indicating the occurrence of drugresistant forms of $\mathrm{TB}$. It would be interesting to analyze the results of a 12-month cycle of treatment with isoniazid or IPT, based on the combination of isoniazid, rifampicin and pyrazynamide in patients with HIV.

\section{CONCLUSIONS}

1) All the analyzed studies concerning the effectiveness of tuberculosis prophylaxis in patients with HIV/AIDS treated with isoniazid showed the effectiveness of this drug.

2) In the compared studies, the isoniazid therapy applied showed no difference in effectiveness according to its duration.

3) The analyzed studies demonstrated a similar effectiveness with respect to the reduction in the level of mortality among patients with TB/HIV/AIDS under the effect of treatment with isoniazid.

\section{REFERENCES}

1. Global AIDS Update: Miles to go: closing gaps, breaking barriers, righting injustices. UNAIDS Joint United Nations Programme on HIV/AIDS 2018 http://www.unaids.org/sites/default/files/media_asset/ miles-to-go_en.pdf (access: 2019.04.03)

2. UNAIDS data 2018. Joint United Nations Programme on HIV/AIDS 2018 http://www.unaids.org/sites/default/files/media_asset/unaidsdata-2018_en.pdf (access: 2019.04.03)

3. Regional Overview 2.2 Eurasia. Global State of Harm Reduction 2016 https://www.hri.global/files/2016/11/15/Eurasia.pdf (access: 2019.04.03)

4. Gokengin D, et al. HIV care in Central and Eastern Europe: How close are we to the target? Int J Infect Dis. 2018; 70: 121-130.

5. Gopalan N, Chandrasekaran P, Swaminathan S, Tripathy S. Current trends and intricacies in the management of HIV-associated pulmonary tuberculosis. AIDS Res Ther. 2016; 26(13): 34.

6. World Health Organisation. Systematic screening for active tuberculosis. Principle and recommendations. World Health Organisation. http:// apps.who.int/iris/bitstream/10665/84971/1/9789241548601_eng.pdf. (access:2018.12.08)

7. WHO treatment guidelines for drug-resistant tuberculosis: 2016.http:// apps.who.int/iris/bitstream/handle/10665/250125/9789241549639-eng. pdf;jsessionid=9CEEEBC27756F53EC61AB4E9987A7CAD?sequen $\mathrm{ce}=1$ (access:2019.01.20).

8. World Health Organization. The shorter MDR-TB regimen. 2016 http://www.who.int/tb/Short_MDR_regimen_factsheet.pdf. (access:2018.12.08)

9. Panel on Antiretroviral Guidelines for Adults and Adolescents. Guidelines for the Use of Antiretroviral Agents in Adults and Adolescents Living with HIV. Department of Health and Human Services. Available at http://aidsinfo.nih.gov/contentfiles/lvguidelines/ AdultandAdolescentGL.pdf. (access:2018.12.08).

10. WHO. Tuberculosis, fact sheet. http://www.who.int/mediacentre/ factsheets/fs104/en/index.html (access:2018.12.08).

11. WHO. Global tuberculosis report 2018. https://www.who.int/tb/ publications/global_report/en/ (access:2018.12.08).

12. The Global HIV/AIDS Epidemic. http://files.kff.org/attachment/FactSheet-The-Global-HIV-AIDS-Epidemic (access: 2018.12.06).

13. Tuberculosis surveillance and monitoring in Europe 2018. Surveillance Report WHO Regional Office for Europe. https://ecdc.europa.eu/sites/ portal/files/documents/ecdc-tuberculosis-surveillance-monitoringEurope-2018-rev1.pdf (access: 2019.04.03) 
14. Tuberculosis Regional Eastern European and Central Asian Project (TB-REP). WHO Regional Office for Europe 2017. http://www.euro. who.int/_data/assets/pdf_file/0003/351291/TB_REP_Mid-term_ update_English.pdf?ua=1 (access: 2019.04.03)

15. UNAIDS. 2018 Global AIDS Update; July 2018. United Nations. Reinvigorating the AIDS response to catalyse sustainable development and United Nations reform: Report of the Secretary-General. June 2017. http://www.unaids.org/sites/default/files/media_asset/UNGA72reportUNSG_en.pdf (access: 2019.04.03)

16. Swindells S, Ramchandani R, Gupta A, et al. One Month of Rifapentine plus Isoniazid to Prevent HIV-Related Tuberculosis. N Engl J Med. 2019; 380(11).

17. Vesga JF, Hallett TB, Reid MJA, et al. Assessing tuberculosis control priorities in high-burden settings: a modelling approach. Published online March 20, 2019, http://www.thelancet.com/lancetgh http:// dx.doi.org/10.1016/S2214-109X(19)30037-3 (access: 2019.04.03)

18. Semu M, Fenta TG, Medhin G, Assefa D. Effectiveness of isoniazid preventative therapy in reducing incidence of active tuberculosis among people living with HIV/AIDS in public health facilities of Addis Ababa, Ethiopia: a historical cohort study. BMC Infect Dis. 2017; 17: 5.

19. Abossie A, Yohanes T. Assessment of isoniazid preventive therapy in the reduction of tuberculosis among ART patients in Arba Minch Hospital, Ethiopia. Ther Clin Risk Manag. 2017; 13: 361-366.

20. Maharaj B, Gengiah TN, Yende-Zuma N, Gengiah S, Naidoo A, Naidoo K. Implementing isoniazid preventive therapy in a tuberculosis treatment-experienced cohort on ART. Int J Tuberc Lung Dis. 2017 21(5): 537-543.

21. Zunza M, Gray DM, Young T, Cotton M, Zar HJ. Isoniazid for preventing tuberculosis in HIV-infected children. Cochrane Database Syst Rev. 2017; 8:CD006418. doi: 10.1002/14651858.CD006418.pub3.

22. Charalambous S, Grant AD, Innes C, Hoffmann CJ, Dowdeswell R, Pienaar J, Fielding KL, Churchyard GJ. Association of isoniazid preventive therapy with lower early mortality in individuals on antiretroviral therapy in a workplace programme. AIDS. 2010; 24 Suppl 5: S5-13.

23. Podlekareva DN, Schultze A, Panteleev A, et al. One-year mortality of HIV-positive patients treated for rifampicin- and isoniazid susceptibletuberculosis in Eastern Europe, Western Europe, and Latin America. AIDS. 2017; 31(3): 375-384.

24. Nagu TJ, Aboud S, Mwiru R, Matee MI, Rao M, Fawzi WW, Zumla A, Maeurer MJ, Mugusi F. Tuberculosis associated mortality in a prospective cohort in Sub Saharan Africa: Association with HIV and antiretroviral therapy. Int J Infect Dis. 2017; 56: 39-44.

25. da Silva Escada RO, Velasque L, Ribeiro SR, Cardoso SW, Marins LMS, Grinsztejn E, da Silva Lourenço MC, Grinsztejn B, Veloso VG. Mortality in patients with HIV-1 and tuberculosis co-infection in Rio de Janeiro, Brazil associated factors and causes of death. BMC Infect Dis. 2017; 17(1): 373.

26. Badje A, Moh R, Gabillard D, et al. Effect of isoniazid preventive therapy on risk of death in west African HIV-infected adults with high CD4 count: long-term follow up of the Temprano ANRS 12136 trial. Lancet Glob Health 2017; 5: e1080-89.
27. Samandari T, Agizew TB, Nyirenda S, Tedla Z, Sibanda T, Mosimaneotsile B, Motsamai OI, Shang N, Rose CE, Shepherd J. Tuberculosis incidence after 36 months' isoniazid prophylaxis in HIVinfected adults in Botswana: a posttrial observational analysis. AIDS. 2015; 29(3): 351-9.

28. Golub JE, Cohn S, Saraceni V, Cavalcante SC, Pacheco AG, Moulton LH, Durovni B, Chaisson RE. Longterm protection from isoniazid preventive therapy for tuberculosis in HIV-infected patientsin a medium-burden tuberculosis setting: the TB/HIV in Rio (THRio) study. Clin Infect Dis. 2015; 60(4): 639-45.

29. Sumner T, Houben RM, Rangaka MX, Maartens G, Boulle A, Wilkinson RJ, White RG. Post-treatment effect of isoniazid preventive therapy on tuberculosis incidence in HIV-infected individuals on antiretroviral therapy. AIDS. 2016; 30(8): 1279-86.

30. Samandari TM, Mosimaneotsile B, Agizew T, Nyirenda S, Tedla Z, Sibanda T, et al. Randomized, placebo-controlled trial of 6 vs 36 months isoniazid TB preventive therapy for HIV-infected adults in Botswana. In: Program and Abstracts of Conference on Retroviruses and Opportunistic Infections; 8-11 February 2009; Montreal, Canada.

31. Martinson NB, Barnes G, Msandiwa R, Moulton L, Gray G, McIntyre $\mathrm{J}$, et al. Novel regimens for treating latent TB in HIV infected adults in South Africa: a randomized clinical trial. In: Program and Abstracts of Conference on Retroviruses and Opportunistic Infections; 8-11 February 2009; Montreal, Canada.

32. Swaminathan S, Menon PA, Perumal V, Santhanakrishnan R, Ramachandran R, Chinnaiah $\mathrm{P}$, et al. Efficacy of a 6-month vs a 36-month regimen for prevention of TB in HIV-infected persons in India: a randomized clinical trial. In: Program and Abstracts of Conference on Retroviruses and Opportunistic Infections; 16-19 February 2010; San Francisco.

33. Zar HJ, Cotton MF, Strauss S, Karpakis J, Hussey G, Schaaf HS, et al. Effect of isoniazid prophylaxis on mortality and incidence of tuberculosis in children with HIV: randomised controlled trial. BMJ 2007; 334:136

34. Grant AD, Fielding KL, Charalambous S, Chaisson RE, Churchyard GJ. Why have trials of isoniazid preventive therapy among people with HIV infection not demonstrated an effect on mortality? AIDS 2010; 24 (suppl 5): S15-S18.

35. Global HIV \& AIDS statistics - 2018 fact sheet http://www.unaids.org/ en/resources/fact-sheet (accessed 08.12.2018).

36. Haileyesus Getahuna, Reuben Granichb, Delphine Sculiera, Christian Gunneberga, Leopold Blanca, Paul Nunna and Mario Raviglionea, Barriers and solutions, AIDS 2010; 24 (suppl 5): S57-S65.

37. Briggs MA, Emerson C, Modi S, Taylor NK, Date A. Use of isoniazid preventive therapy for tuberculosis prophylaxis among people living with HIV/AIDS: a review of the literature. J Acquir Immune Defic Syndr. 2015; 68.

38. Ayele HT, Mourik MS, Debray TP, Bonten MJ. Isoniazid Prophylactic Therapy for the Prevention of Tuberculosis in HIV Infected Adults: A Systematic Review and Meta-Analysis of Randomized Trials. PLoS One. 2015; 10(11): e0142290.

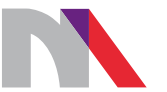

Ministry of Science and Higher Education

Republic of Poland

Generation of the DOI (Digital Object Identifier) - task financed under the agreement No. 618/P-DUN/2019 by the Minister of Science and Higher Education 